\title{
Un extraño visitante. Lecciones patrimoniales de la Cartuja recuperada, 1989-1992-2017
}

\begin{abstract}
Recuperar como volver a mirar, para reconstruir, para intervenir. Y volver a mirar, para interpretar una de las intervenciones en el patrimonio histórico andaluz más relevantes, realizada a finales de los 80 y aún hoy vigente e incomprendida en muchos de sus aspectos: recuperar la Cartuja recuperada. La intervención llevada a cabo en el monasterio de Santa María de las Cuevas (Sevilla) ejecuta un proyecto que, por primera vez en el ámbito cultural andaluz, traslada la cuestión metodológica del "trato con las cosas cubiertas por las cenizas del tiempo" al proyecto de arquitectura. Nos lo cuenta...
\end{abstract}

José Ramón Moreno-Pérez | Universidad de Sevilla

Marta García-Casasola | Instituto Andaluz del Patrimonio Histórico, Universidad de Sevilla

URL de la contribución <www.iaph.es/revistaph/index.php/revistaph/article/view/3986>

\section{DE CÓMO LLEGAMOS AL 92}

\section{Primer movimiento: una desconocida presencia}

Adormecido por la falta de actividad, el edificio sesteaba sin adivinar lo que se le venía encima. Había cambiado de administración hacía poco tiempo, pero la nueva -pese a su proximidad- tampoco se había notado mucho, salvo porque mostraba una curiosidad enfermiza hacia aquel amasijo de piezas que configuraban su cuerpo y desafiaba la comprensión de cualquier visitante.

Era consciente de que el tiempo vivido le había jugado una mala pasada y ahora se veía tendido "como gato al sol", con la naturalidad de un cuerpo que se arrellana en el sitio que día tras día lo aposenta.

La soledad de sus espacios apenas frecuentados durante años comenzó a romperse, cuando aparecieron pequeños grupos de ansiosos visitantes, que con una charla interminable celebraban no sé qué descubrimientos o simplemente mostraban su sorpresa por la apariencia de las estancias que recorrían. Se detenían, miraban, comentaban y vuelta a empezar, yo me sentía como uno de esos cacharros mecánicos capaces de inducir mediante sus movimientos un masaje de efectos sorprendentes en los humanos que lo usan. Sólo que yo no hacía nada, permanecía en mi ser, sin apenas manifestarme. Pero ellos, animados por un fervor que no había visto antes, se esforzaban por identificar la edad o la procedencia de los elementos que atraían su atención, hablando del momento que ocupaba en mi biografía imaginada, todo ello sin aclarar cuáles eran sus intenciones; sin embargo, yo atesoraba en mi memoria otras ocasiones, en las que había sucedido algo parecido e intuía dónde terminaría todo aquello.

$[\ldots]$

Decía Josep Quetglas que el primer arquitecto no fue Teseo sino Ariadna, aquella mujer capaz de dar orientación, con el tendido de su hilo rojo, a quien visitara el laberinto, salvándolo de la irremisible pérdida a la que aquella construcción lo condenaba.

Algo parecido debieron de afrontar aquellos extraños visitantes de los que nos habla la fábrica de Cartuja, al conducir sus pasos por medio de un laberinto, sin guía que los condujera. Tuvieron que identificar los elementos de su arquitectura, trazar mapas de sus espacios y articulaciones, identificar su particular topología de muñecas rusas. Revelar el alcance de un patrimonio que, como documento del pasado, desafía nuestra capacidad de significar la materialidad adquirida (CHOAY, 2007), una tarea contemporánea que esos visitantes heredaron de una cultura recuperada, donde lo genealógico era la acción capaz de dar continuidad a una relación rota por la Modernidad. 


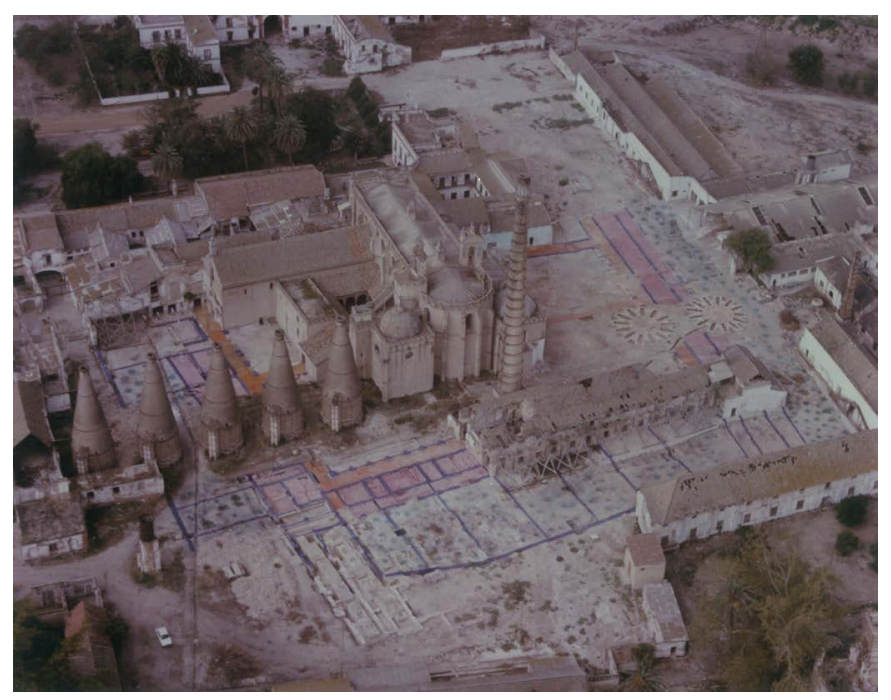

Imagen aérea de la zona del claustro de monjes después de las demoliciones donde se identifica la traza del claustrón sobre los restos arqueológicos | foto Informe sobre el estado de las obras de conservación del conjunto monumental de la Cartuja de Sevilla, Centro de Documentación del Centro Andaluz de Arte Contemporáneo

Con ello, una sociedad cansada de la preeminencia del presente compensa su hastío trasladando esa quietud del pasado a la agitación contemporánea. Es por eso que los extraños visitantes se entusiasmaban en su visita, para finalmente establecer un punto de vista capaz de darles pie para construir su interpretación: una forma del edificio, una arquitectura; ese es su legado, incorporado ahora a la historia efectual de la fábrica.

\section{Segundo movimiento: jestamos rodeados!}

La piel de mi cuerpo sentía -años después del comienzo de aquellas desconocidas visitas- una cierta desazón: en aquel entorno agrícola en el que durante siglos había existido, se notaba la presencia de seres y máquinas que, a diferencia de los anteriores, se comportaban de manera particular y producían unos efectos que me desasosegaban.

Los caminos que antaño habían permitido que la gente viniera a mis puertas estaban siendo sustituidos por otros, extrañas zanjas atravesaban en diversas direcciones los campos de cultivo y en la bucólica orilla del río se agolpaba una intensa actividad y los animales que antes venían a refugiarse en mis huertas y jardines habían desaparecido. Mi entorno estaba siendo inva- dido. Decididamente comenzaba para mí otro momento de mi vida, de una vida azarosa hecha a golpes de añadidos y destrucciones, de novedades y permanencias, de violaciones y caricias que punteaban como las notas de una partitura la música callada de mis estancias.

\section{$[\ldots]$}

Toda arquitectura -dice Derrida- tiene su ruina en su origen y le acompaña como marca indeleble toda su vida, le ocurre como a la visibilidad que no tiene otro comienzo que la ceguera. Por lo tanto, observar la arquitectura a través de sus procesos de deterioro, de su envejecimiento, modifica una manera de comprenderla heredada de lo moderno.

Es esta una lección, que enuncia un principio de continuidad, presente en una apuesta patrimonial que intenta resolver las contradicciones introducidas por el principio radical de la novedad absoluta.

\section{Tercer movimiento: aquel grupo de entusiastas}

Y de pronto llegaron para acompañarme hacia mi nueva vida, estuvieron conmigo un período tan largo, que empezaron a recordarme a aquellos hombres cubiertos por unas zayas claras que durante siglos permanecieron en la vida y la muerte junto a mí: en el refectorio comían y en mis pequeñas celdas dormían y estudiaban, en la huerta espléndida hacia el norte del recinto, labraban sus plantaciones o recogían los frutos de sus árboles. Al igual que ellos, estos también eran activos, pero se dedicaban a cosas más técnicas, hablaban de mi fábrica, de los espacios diversos que la componían, intentaban entenderlos a sabiendas de la coincidencia de trazas que lo configuraban $y$, al mismo tiempo, imaginaban a qué podrían dedicarse en el futuro, repetían siempre una fecha que debería ser muy importante: el 92.

Formaban grupos diversos, cada uno dedicado a un menester: unos sabían mucho de mi pasado, hablaban con familiaridad de él, de mis orígenes, de aquellos que me fundaron, de la relación que mantenía con la ciudad o la Orden, de los modos de vida y de las fases y dedicaciones que había tenido; otros estaban concentrados en sólo una parte de mi fábrica: la iglesia y el refectorio, el conjunto de afuera, el pequeño claustro de legos 
o los hornos de la Fábrica; mientras que otros hablaban del futuro que comenzaría con el 92, qué iba a ocurrir conmigo, a qué me debía prestar, a oficina, museo, tal vez vivienda... no se decidían, preparaban informes de muchas páginas que luego discutían fuera de aquí; muchas visitas tuvimos esos años, debían de ser importantes, pues estos chicos se comportaban ceremoniosamente y callaban más que hablaban durante las mismas. Probablemente por su mediación, mi cuerpo fue adquiriendo una conformación en la que algunos de los restos de mis diversas vidas atestiguaban que sus lugares pertenecían a un largo tiempo: aquí y allí se hacía presente un canalillo del antiguo sistema de irrigación o un fresco oculto por las capas de cal, también volvieron piezas prestadas a otras instituciones de la ciudad, regresaron ocupando su puesto, eran espectaculares los hornos desembarazados de los elementos fabriles que lo habían rodeado o los recuperados pabellones románticos de la huerta o el conjunto de la Capilla de Afuera.

Puedo aún recordar el eco apagado de sus nombres, no quiero olvidar ninguno y de todos aquellos que prestaron su oficio, tan antiguo como mi existencia, legión eran, cuando por la mañana temprano año tras año volvían para seguir una tarea que se hacía eterna. Hoy, cuando recorren otros visitantes esos espacios, aún se puede escuchar el sonido de sus herramientas, las voces de sus colaboraciones, mezclados con otros más antiguos, como los pasos en el patio del claustro o las luces que ahora entran por el hueco de arriba de la biblioteca.

\section{$[\ldots]$}

La intervención llevada a cabo en el Monasterio de Santa María de las Cuevas ejecuta un proyecto que, por primera vez en el ámbito cultural andaluz, traslada la cuestión metodológica del "trato con las cosas cubiertas por las cenizas del tiempo" al Proyecto de Arquitectura, buscando hallar un modo de regular la intervención sobre los bienes patrimoniales declarados por las instituciones del patrimonio. El Conjunto Monumental del Monasterio se convierte así en un laboratorio en el que ensayar modos de articulación e instrumentación innovadora que asegure la relevancia de la recuperación de su Fábrica desde dos presupuestos confrontados y problemáticos: hacer

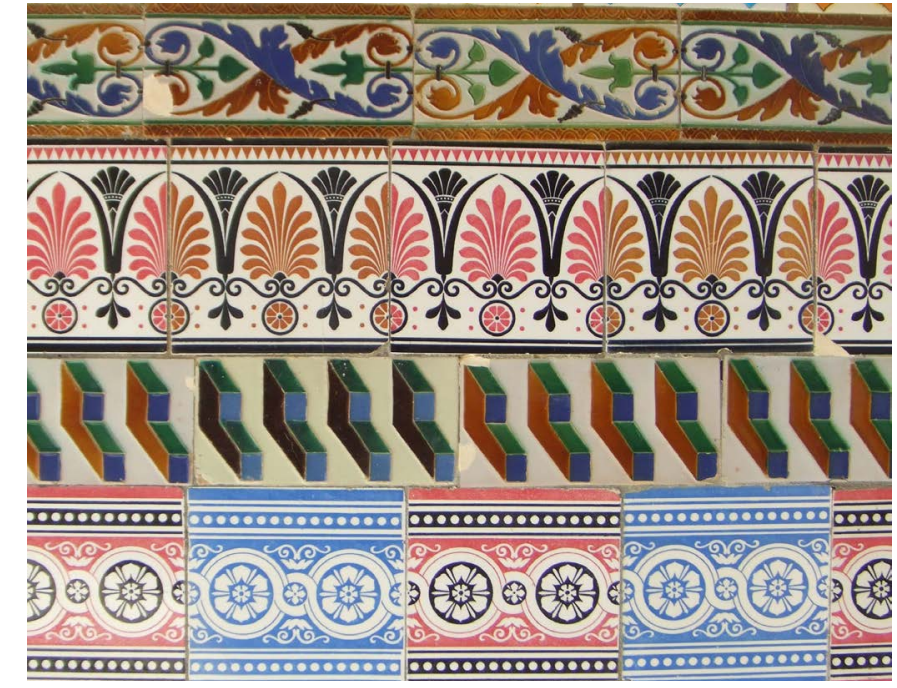

Collage de azulejos. Arco de procuración | foto Marta García-Casasola, 2011

justicia a su pasado y ahorificarlo en el presente, a ello debe añadirse un tercero: convertirse en un modelo-horizonte para cualquier práctica patrimonial innovadora.

Ensamblar en un dispositivo hermenéutico, compartido, las diferentes lecturas críticas, capaces de valorar aquello que identifica la configuración temporal y material de su espacialidad formativa, era un primer paso -que reiteradamente se hizo presente a lo largo de aquellos añospara armonizar los resultados diversos de un modo de trabajo, que había apostado por dividir -para luego conjuntar- las partes significativas del Monasterio, intervenidas por enfoques arquitectónicos diferentes. ¿Qué debe permanecer frente a lo que puede desaparecer, de aquel amasijo "en ruina", mediante su incorporación a la transformación que -como único mecanismo posible de actuación- le dará una nueva vida y otra identidad?

Contestar esta pregunta a través del registro complejo de sus diferentes estratos, donde la relevancia de sus diferentes dataciones no suprimía la acción de la memoria, necesitó de una particular imaginación, que proyectaba un imaginario cambiante -más o menos compartido por los actores de sus diferentes representaciones. A través de la construcción de imágenes que se entrelazaban con diversas estratigrafías y con el almacenamiento virtual de una objetualidad aflorada o encontrada, en estra- 


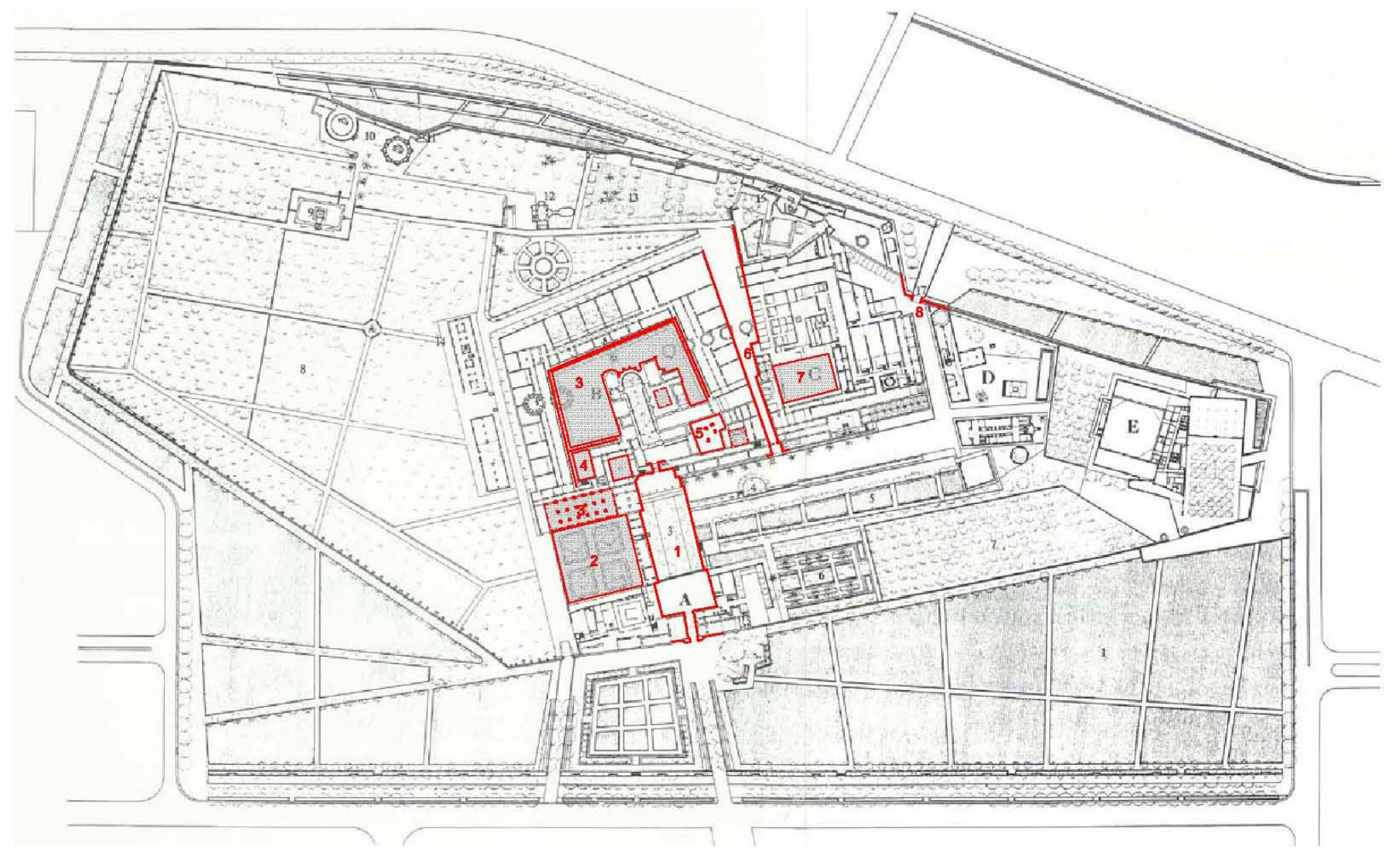

Espacios intermedios del Monasterio de Santa María de las Cuevas: 1.- Entrada principal. 2.- Jardín del Padre Nuestro y Jardín del prior. Acceso al CAAC. 3.Claustrón. 4.- Memorial del agua. 5.- Biblioteca. 6.- Pasaje de procuración. 7.- Claustro de Legos. 8.- Puerta del río | plano Marta García-Casasola sobre la planimetría de proyecto publicada en La Cartuja Recuperada

tos que, sin formar parte de una historia oficial, tuvieron que ser incorporados a ese imaginario en proceso.

Un tiempo entendido como construcción cultural (AGUDO TORRICO, 2012), un proceso en permanente transformación que incorpora al individuo y a lo colectivo, a la biografía y a la historia como relatos temporales. Un tiempo que hemos denominado fenomenológico porque no puede entenderse sino a partir de la comprensión de que cada cultura construye su propia percepción del tiempo.

\section{Cuarto movimiento: el desafío de la autenticidad} Heme aquí, devuelto a la vida, debo confesar que no ha sido fácil pasar por este envite. Traspasar el acontecer de épocas me ha sido permitido durante la mayor parte de mi vida, porque ellas pertenecían en su continuo cambio a un mundo emergente pero único: viví época de renacimientos, junto a estilos tardíos; rupturas culturales mezcladas con el permanecer de la tradición; todo esto parece ahora desaparecido.

Llevo un tiempo revisando mi nueva contextura, todo mi cuerpo está ahora más en consonancia con las actividades que albergo, aunque se pueda reconocer en todas esas partes un viso de unidad; quizás sea que mi piel sigue envolviéndolo todo con una robustez capaz de mostrar unitariamente una corporeidad compleja. Recorre mi fábrica una información difusa que me hace consciente de quién soy ahora $y$, aunque a veces me asalta la perplejidad, puedo decir que soy consciente de que me identidad se funda en el tiempo; sin embargo, a veces me asalta una pregunta: y después, que vendrá. 
He escuchado que me he convertido en un modelo a seguir, que el proceso que me transformó en lo que soy es "piedra de toque" para distinguir el sonido de otras prácticas similares, aunque sé, que soy en esto: hijo de otro tiempo y fruto de una coyuntura irrepetible, esa que celebra ahora un coro de voces, entre las que se encuentra la mía.

Claro que también pagué por ello: me abrieron al flujo de una movilidad monstruosa, yo que había vivido un tiempo detenido y eternamente repetido, banalizaron el valor de mis espacios por medio de un imaginario cambiante, que como una envoltura virtual antecede a mi propio ser, mostrando una apariencia cambiante, lo llaman espectáculo; mi significación también ha sido trastocada mediante prácticas culturales que me convierten en soporte pasivo de otros procesos de significación: musicales, plásticos, comunicativos o celebratorios, comenzando por aquellos seis meses en los que fui enseña de otras instituciones.

Mi autenticidad es híbrida, quizás siempre lo fue, pero ahora perdido los eslabones que garantizaban mi cohesión, mis partes flotan disponibles para componerse en procesos externos y diversos: soy el Monasterio, la Fábrica, el cuartel, una celda del panal de la Colmena, la sede del IAPH, el CAAC, la UNIA, el set para una música globalizada, un punto en la guía de cualquier turista necesitado de pasado,...

\section{$[\ldots]$}

Con la idea de autenticidad, se define un horizonte que desafía en cada caso al proyecto arquitectónico, que como instrumento técnico, permite adelantar en el presente -visibilizándolo- un tiempo por venir: partiendo del entendimiento de una realidad, desvelando la estructura de su objetualidad, no estamos en condiciones de acceder a verdades, sino trazar relaciones de las que emerja una conformación futura.

Por tanto, el proyecto es deconstrucción, su procesualidad nos permite establecer las dicotomías sobre las que se enuncia la autenticidad de lo que se proyecta, sea contexto, temática, objetualidad o proceso; a la vez que se muestra la artificialidad de la elección de la ficticia jerarquía establecida por la dicotomía que lo estructura: monasterio/fábrica/cuartel, por ejemplo. Es en ese momento, en el que el proyecto abre un espacio de posibilidades -tan ficticio como real- entre ambos términos, donde se puede alojar la diseminación de la significación de los polos y permitir que cada uno de ellos se haga presente en el otro.

Esta es una de las evidencias que se muestran en el juego al que el edificio recuperado nos invita y son en sus espacios intermedios en los que la partida comienza. El edificio está imbuido, así, de una determinada museología de sí mismo, cuyos elementos y relaciones -formada por fragmentos incorporados a espacios contemporáneos- exponen sus significaciones y conformaciones.

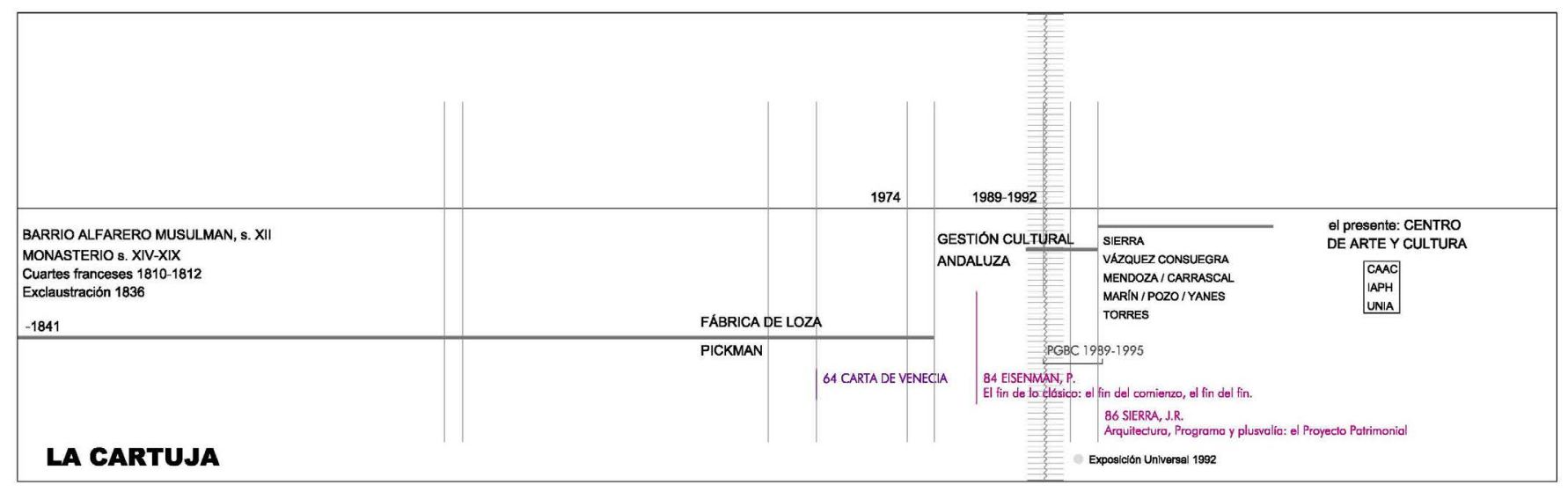

Cronología de las intervenciones en el Monasterio de Santa Ma de las Cuevas | gráfico Marta García-Casasola, 2010 

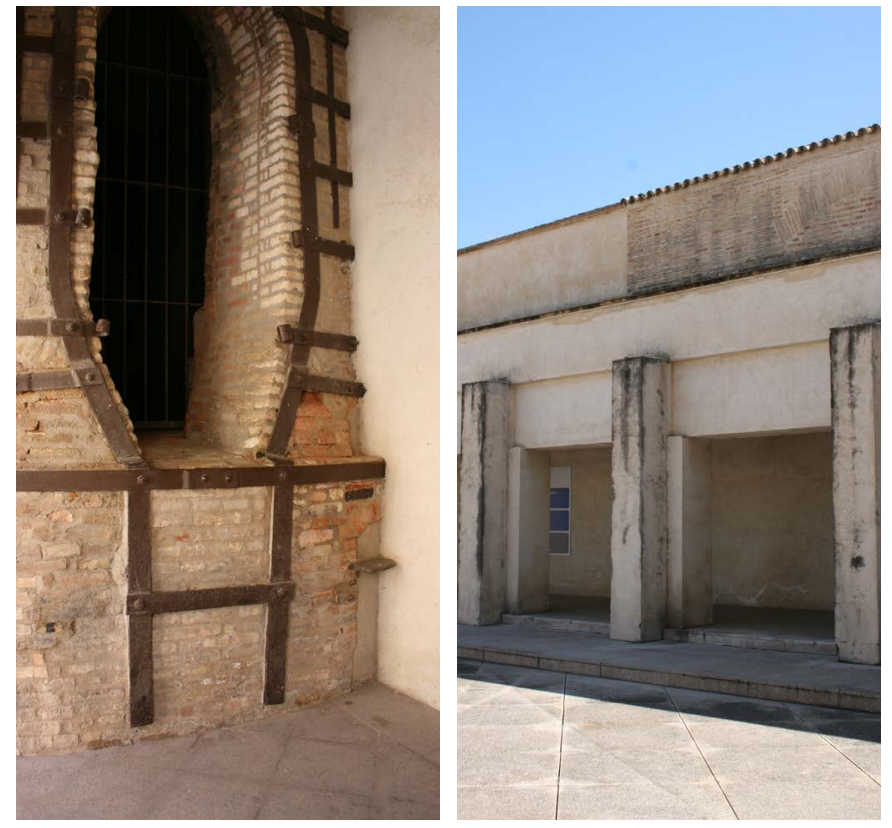

A la izquierda, chimenea "superpuesta" sobre la traza del claustrón. A la derecha recuperación del claustrón. Proyecto de los hermanos Sierra | foto Marta GarcíaCasasola

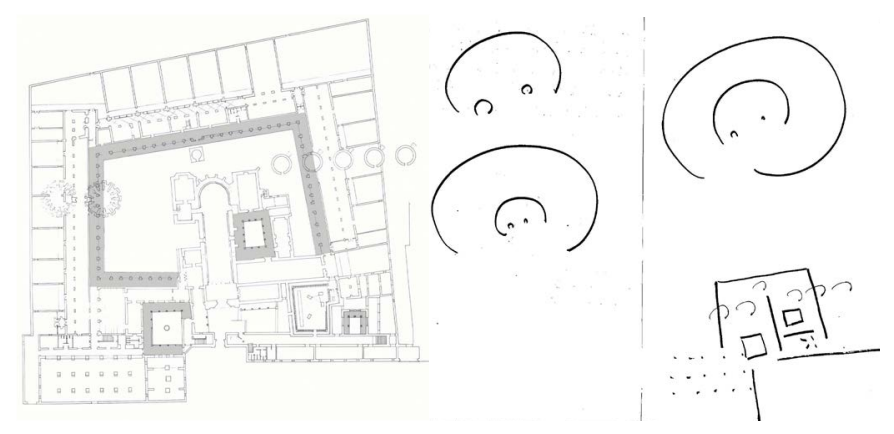

Intervención de los hermanos Sierra en el Claustro de Monjes de la Cartuja de Santa María de las Cuevas. A la izquierda, claustrillo, claustro y claustrón: galerías para girar en torno a un vacío. A la derecha: Lectura de la Cartuja. Identificación de trazas concéntricas a diferentes escala | plano Nieves Sánchez Alfonso, 2010 (sobre la planimetría de proyecto publicada en La Cartuja Recuperada); croquis Cuaderno de tesis 5/6, Marta García-Casasola, 2011

La memoria, que de alguna manera también opera desde la deconstrucción, se traslada al ejercicio de rememoración permanente que nos ofrece la museografía y la museografía en este tipo de proyectos culturales. La relación objeto/espectador/actor resulta clave para comprender los ejercicios proyectuales ante los que nos situamos en los que la selección del discurso forma parte de la traslación del recuerdo.

\section{PAS DE DEUX}

Siempre el caminar por mis estancias va acompañado y acompasado a los espacios que ellas contornean o allí donde se hallan insertas, por ello, siempre mis visitantes estarán entre dos mundos, entre dos cortes de cielos, entre dos luminosidades; esta sensación, sea consciente o no, es mi aportación a la experiencia de quienes me visitan, la enunciación de una museografía de su elocuencia.

Su horizonte de experiencia está por ello inserto en una sucesiva expansión, es como un vector, cuya punta nunca alcanza a tocar la línea curva a la que se dirige. Una secuencia que termina en el envés de donde comenzó: en la piel del recinto.

\section{$[\ldots]$}

Hay quien imaginó la fábrica recuperada a partir de una mirada fractal, que complejiza la concepción tipológica del espacio claustral: claustrillo, claustro, claustrón, para hacernos consciente de la miríada de experiencia que nos aguarda en esa arquitectura. Sólo su recorrido hace posible su disfrute, pues se convierte en un juego que juega con sus caminantes; ello hace necesario que su configuración esté estructurada por pivotes que conducen el giro y la articulación o a la inserción de piezas cuya escala mide sus contornos o la cesura del camino que corta la masa formal o ...

\section{$[\ldots]$}

Hay algo que se repite cuando me aproximo a este lugar, desde lejos y de cerca. El río marca un límite y una estrategia de defensa apoyada en un muro circundante que me obliga a rodear, en este caso para descubrir el acceso, los accesos, que son dos y muy diferentes. Recorridos muy largos, alrededor de o junto a vacíos, diferentes, recorridos sin rumbo, cargados de extrañamientos, a través de espacios acompasados, compuestos, a pesar de todo.

Todo ello te sucederá si vienes a verme, palabra de Cartuja. 


\section{BIBLIOGRAFÍA}

- AA. VV. (1992) La Cartuja Recuperada. Sevilla 1986-1992. Sevilla: Consejería de Cultura y Medio Ambiente Junta de Andalucía, 1992

- AGUDO TORRICO, J. (2012) El tiempo de las identidades híbridas. Temporalidades contemporáneas, incluido el pasado en el presente. Sevilla: Instituto Andaluz del Patrimonio Histórico. Consejería de Cultura de la Junta de Andalucía, 2012, pp. 40-53 (PH Cuadernos, n. ${ }^{\circ} 29$ )

- Blumenberg, H. (2000) La risa de la muchacha tracia. Una protohistoria de la teoría (1. ${ }^{\mathrm{a}}$ ed. 1987). Valencia: PreTextos, 2000

- ChOAY, F. (2007) Alegoría del Patrimonio (1. ${ }^{\mathrm{a}}$ ed. 1992). Barcelona: Editorial Gustavo Gili, 2007

- DERRIDA, J.; PEÑALVER, P. (pr.) (1989) La deconstrucción en las fronteras de la filosofía. La retirada de la metáfora (1. ${ }^{a}$ ed. 1987). Barcelona: Instituto de Ciencias de la Educación de la Universidad Autónoma de Barcelona, 1989

- EISENMAN, P. (1984) El fin de lo clásico: el fin del comienzo, el fin del fin. Arqvitectvras, n. ${ }^{\circ} 48$ (La versión inglesa de este artículo se publica en Perspectiva 21, 1984)

- GONZÁLEZ SANDINO, R. (1996) La dificultad de leer una obra de vanguardia. Apuntes de clases de Teoría de la Arquitectura. Escuela Técnica Superior de Arquitectura de Sevilla. Curso 1996-97

- LOWENTHAL, D. (1993) El pasado es un país extraño. Madrid: Akal, 1993

- MORENO-PÉREZ J. R.; GARCÍA-CASASOLA, M. (2013) De-un-lugar-a-otro. Nada es, de esta manera, dado por pasado. El monasterio de Santa María de las Cuevas de Sevilla. ZARCH: Journal of interdisciplinary studies in Architecture and Urbanism, n. ${ }^{\circ}$ 1. Zaragoza: Universidad de Zaragoza, 2013, pp. 189-191

- NAVARRO BALDEWEG, J. (2001) La habitación vacante (1. ${ }^{a}$ ed. 1999). Valencia: Pre-Textos, 2001

- SIERRA DELGADO, J. R. (2005) Arquitectura, programa y plusvalía: el Proyecto Patrimonial. Revista Neutra, n. ${ }^{\circ} 11$, Sevilla: COAS, 2005

- DECRETO 2803, 1964, de 7 de agosto por el que se declaran conjuntos y monumento histórico-artísticos diversas zonas y edificios en la ciudad de Sevilla (la Cartuja de Santa María de las Cuevas se declara monumento histórico-artístico). Boletín Oficial del Estado, n. ${ }^{\circ}$ 220, de 12 de septiembre de 1964 < https://www.boe.es/boe/dias/1964/09/12/pdfs/A12006-12006. pdf> [Consulta: 01/09/2017] 